\title{
Large bowel obstruction caused by a foreign body
}

\author{
Rezacova $\mathrm{M}^{1 *}$ and Pericleous $\mathrm{S}^{2}$ \\ ${ }^{1}$ Department of General Surgery, Kingston Hospital NHS Trust, Galsworthy Road, Kingston upon Thames, Surrey, KT2 7QB, UK \\ ${ }^{2}$ Department of Upper GI Surgery, St George's Hospital NHS Foundation Trust, St George’s Hospital, Blackshaw Road, Tooting, London, SW17 0QT, UK
}

\begin{abstract}
Introduction: Large bowel obstruction is defined as a mechanical or functional obstruction at the level of colon or rectum, not allowing the natural passage of the products of digestion. It typically occurs in the elderly and requires prompt medical/surgical treatment.
\end{abstract}

Case presentation: A 70-year-old Caucasian woman suffering from locked-in syndrome presented to the emergency department with a distended abdomen and absolute constipation for 3 days. Abdominal X-ray showed features of large bowel obstruction.

An emergency scan confirmed large bowel obstruction caused by a foreign body in the patient's rectum with likely surrounding reactive mural thickening.

Conclusion: All the numerous causes of large bowel obstruction need to be considered and addressed during history taking, examination and forming of a differential diagnosis.

As in our case, CT scanning is invaluable in forming a diagnosis and cause of large bowel obstruction. It can quickly guide management of such cases.

\section{Introduction}

Large bowel obstruction (LBO) is defined as a mechanical or functional obstruction at the level of colon or rectum, not allowing the natural passage of the products of digestion [1]. It typically occurs in the elderly and requires prompt medical or surgical treatment. The urgency of management is driven by the risk of rupture in the distended or compromised colon with the danger of faecal peritonitis [2].

Typical clinical features of LBO are: abdominal pain due to distension and colic; abdominal distension due to retention of faeces and flatus; constipation; non-passage of faeces or flatus (signifying complete obstruction); peritonism (if perforation has occurred) and vomiting [3].

Statistically, the three most common causes of mechanical LBO are carcinoma of the colon (50-60\%), diverticular disease (30\%) and sigmoid volvulus (3-8\%) [4]. Less common causes include strictures (from inflammatory bowel disease, ischaemia and radiation), intussusception, adhesions (less than 1\%) and faecal impaction. Pseudo-obstruction (Ogilvie's syndrome), a condition characterised by acute dilatation of the colon in the absence of mechanical obstruction, presents with similar clinical features to an organic obstruction with the same potential complications, but is usually associated with another illness [5-6].

\section{Case presentation}

\section{Medical history}

A 70-year-old Caucasian female suffering from Huntington's disease causing locked-in syndrome presented to the emergency department with her relatives with a very distended abdomen and not having opened her bowels for 3 days. The family reported no history of vomiting, but they had noticed some retching.
Due to the difficulties in communicating with the patient, the majority of the history was provided by the family who were also the main carers.

Other than Huntington disease, the patient had no significant past medical history and was not on any regular medication. Her feeding was administered through a gastrostomy tube which had been last changed 2 years prior to this presentation. She had no history of major abdominal surgery. The family did not report any weight loss or rectal bleed. There was no family history of bowel disease or abdominal cancers.

\section{Clinical features}

On clinical examination, the patient had a markedly distended abdomen which had no features of peritonitis. Abdominal examination caused noticeable discomfort to the patient. On auscultation she had obstructive bowel sounds.

Rectal examination proved difficult due to patient positioning and pain so was not completed.

The patient was very nauseous and continued to wretch throughout the clinical examination despite antiemetic medication.

\section{Investigations}

Urgent chest and abdominal X-rays performed in the emergency department (Figures 1 and 2) showed features of large bowel obstruction

Correspondence to: Rezacova M, MD, Department of General Surgery, Kingston Hospital NHS Trust, Galsworthy Road, Kingston upon Thames, Surrey, KT2 7QB, UK. Email: rezacovamonika@doctors.org.uk

Key words: large bowel obstruction, mechanical obstruction, foreign body, PEG tube sigmoidoscopy

Received: February 03, 2018; Accepted: February 15, 2018; Published: February 19,2018 


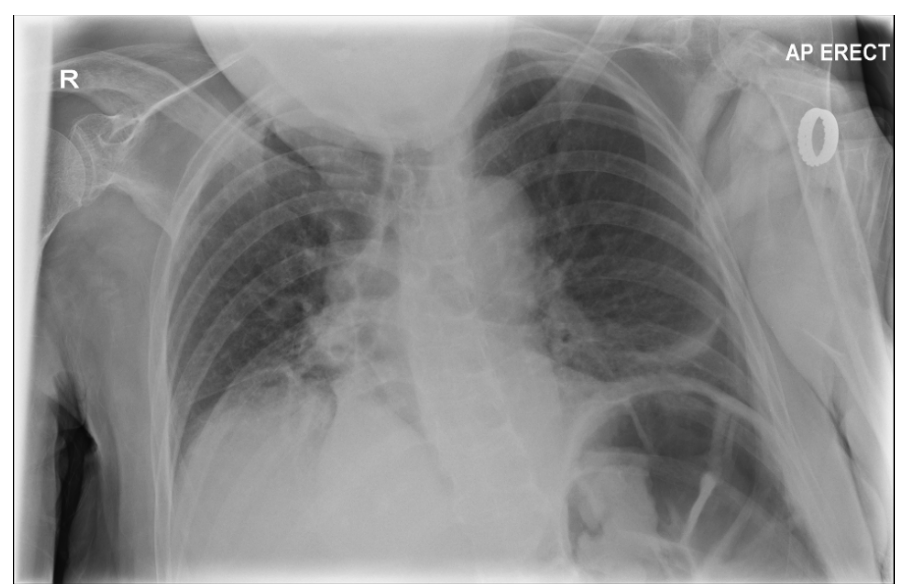

Figure 1. AP erect chest X-ray showing evidence of bowel obstruction

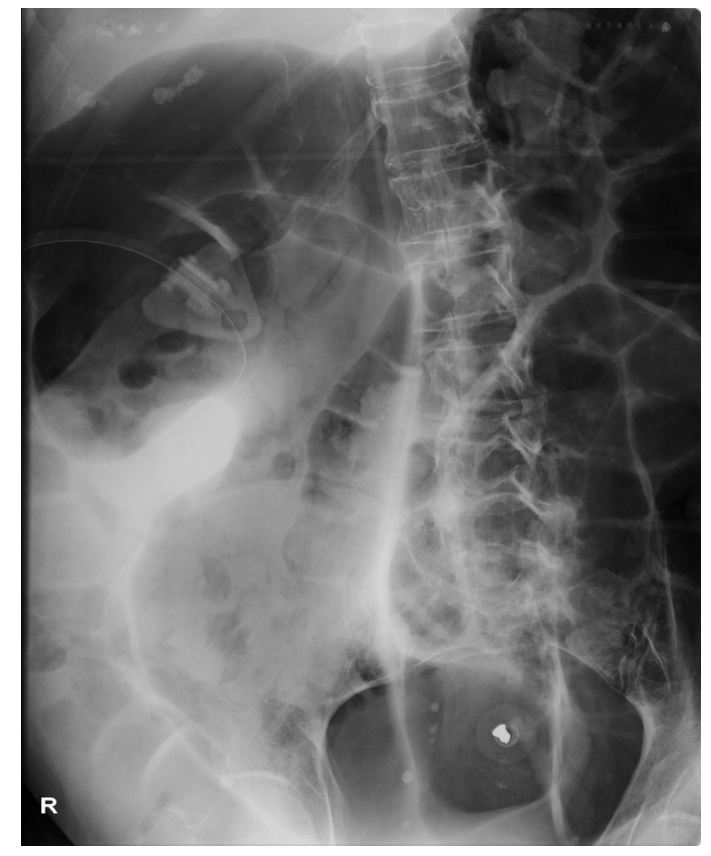

Figure 2. Abdominal X-ray showing evidence of large bowel obstruction

[7]. An urgent contrast enhanced abdominal CT confirmed large bowel obstruction with a foreign body in the pelvis (Figures 3-6) [8].

Formal CT reporting by a radiologist commented that the foreign body appeared similar to a gastrostomy tube bumper within the rectum. There was marked proximal distension of sigmoid colon and faecal loading within the proximal large bowel. The bumper on the existing gastrostomy feeding tube was intact.

\section{Differential diagnosis}

Given the patient's age and comorbidities, the differential diagnoses prior to CT imaging were neoplasm, volvulus, constipation and pseudo-obstruction [9].

Cross sectional imaging, however, unexpectedly suggested a diagnosis of large bowel obstruction due to a foreign body.

\section{Operative findings}

An emergency examination under anaesthetic was performed followed by a sigmoidoscopy where the gastrostomy bumper was retrieved using a grasper (Figure 7). A flatus tube was inserted and left in situ for 12 hours post-operative.

\section{Outcome, prognosis and follow up}

Post operatively the patient began to open her bowels in her normal pattern. She was discharged home 24 hours later.

\section{Discussion}

Bowel obstruction caused by foreign bodies is most often found in the small bowel. The majority of foreign bodies impact just proximal to ileocaecal valve.

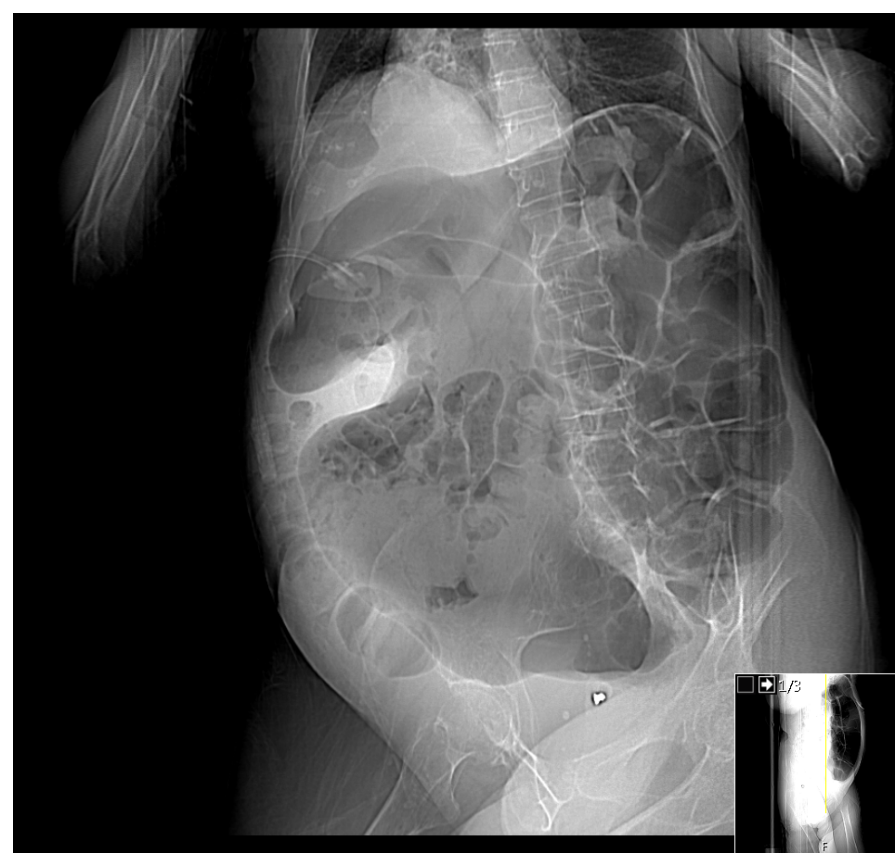

Figure 3. CT AP preview showing evidence of large bowel obstruction

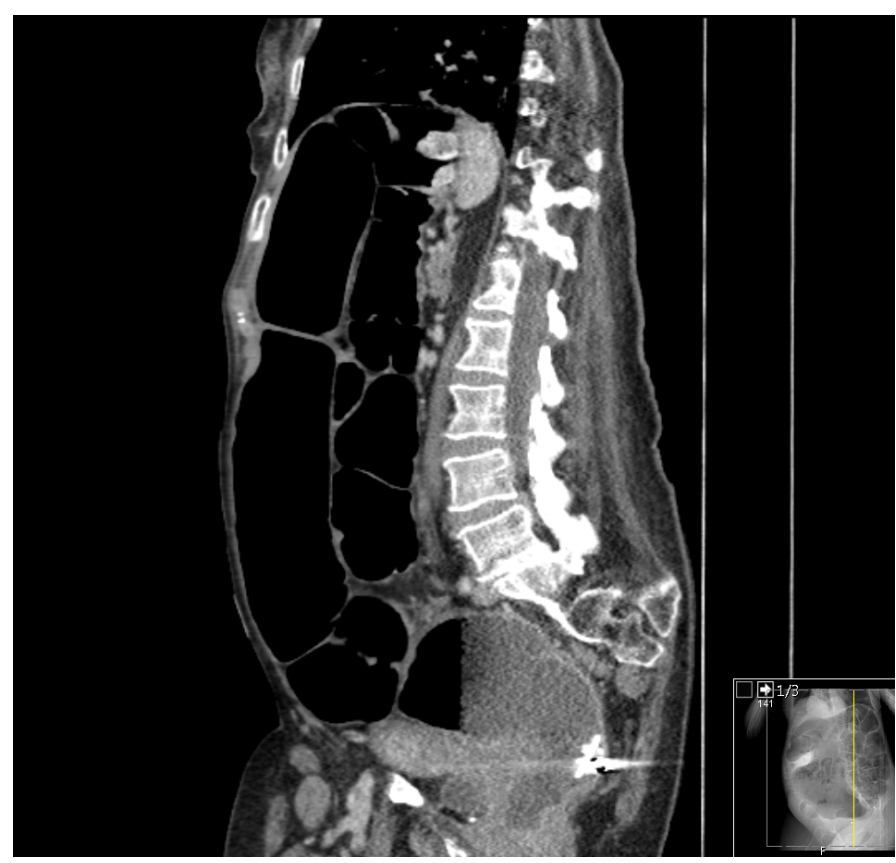

Figure 4. CT AP sagittal section showing evidence of large bowel obstruction and foreign material in rectum 
Large bowel obstruction has many causes all of which should be considered and addressed during history taking, examination and forming a differential diagnosis. The most common causes of large bowel obstruction are neoplastic, volvulus and diverticular disease [10].

Although most cases of large bowel obstruction are managed surgically, there is a shift towards a less invasive approach [11]. The majority of patients with mechanical large bowel obstruction will undergo laparotomy with or without a bowel resection sometimes needing an anastomosis or formation of a stoma. Immediate surgery is indicated if peritonitis is present [12]. If a colonic stricture is identified, stenting is also an increasingly considered option. Self-expandable metal stents are useful particularly in left sided bowel obstruction of malignant origin. These are placed endoscopically as a palliative tool or as a bridge to surgery for patient optimisation [13-14]. In most cases of sigmoid volvulus, endoscopic decompression should be attempted.

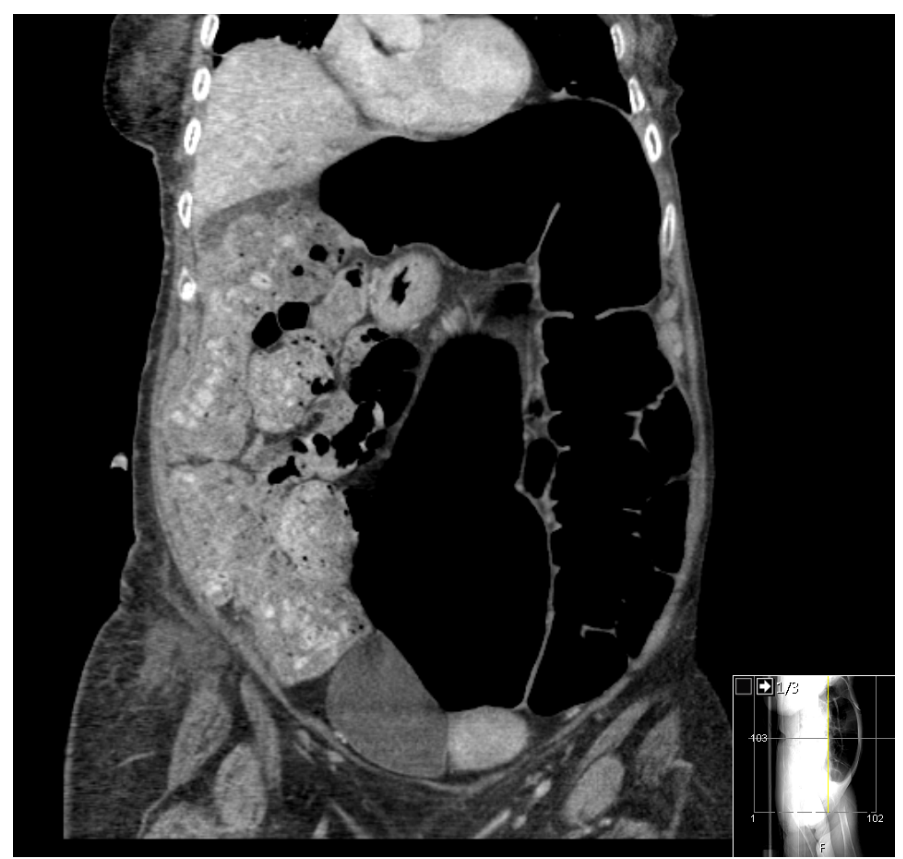

Figure 5. CT AP coronal section showing evidence of large bowel obstruction

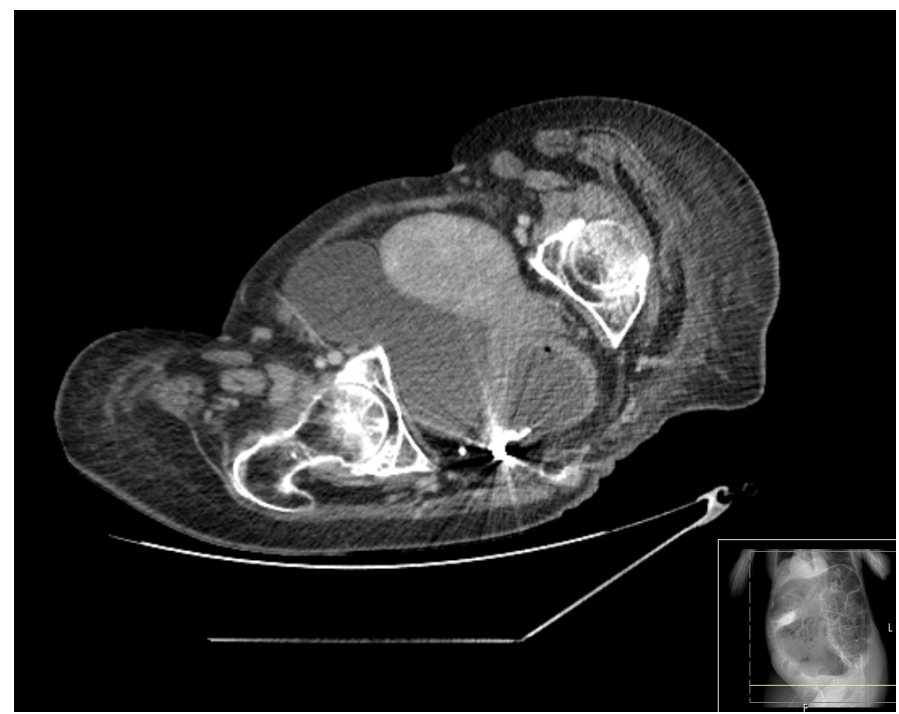

Figure 6. CT AP transverse section showing evidence of foreign material in rectum

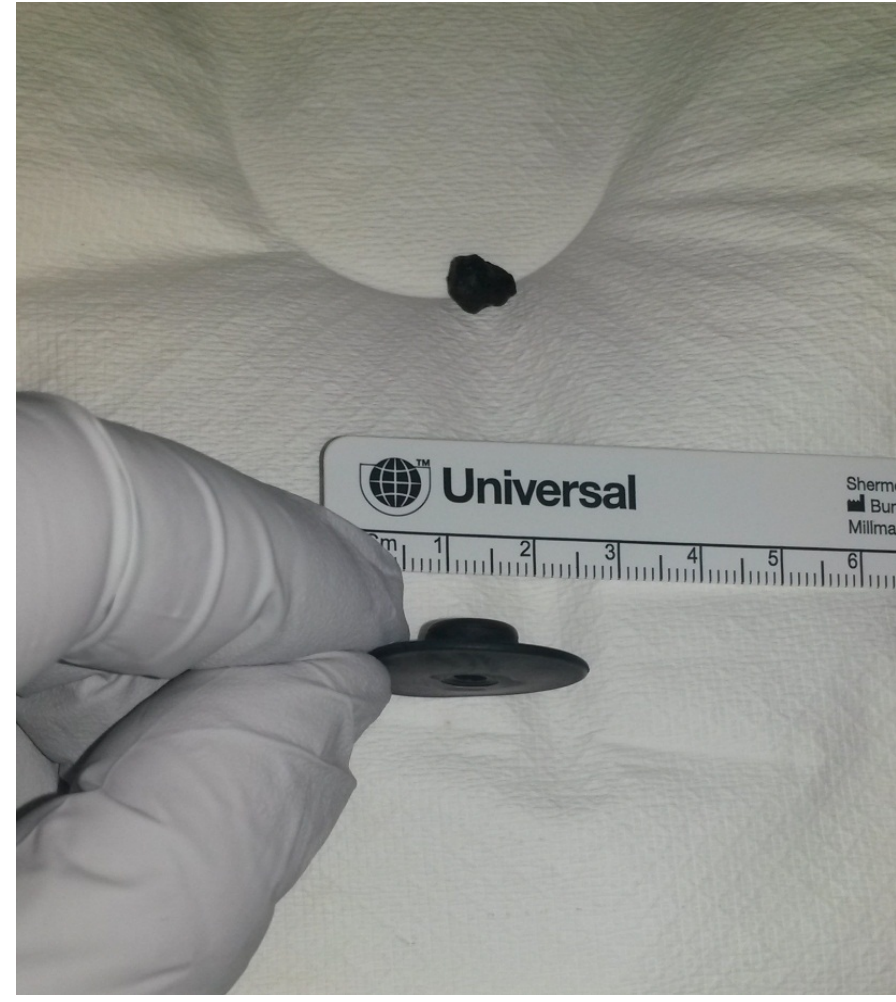

Figure 7. Foreign body removed from rectum (causing large bowel obstruction)

Decompression is achieved in the majority of cases avoiding the need for major surgery. Pseudo-obstruction should be managed conservatively by addressing the patient's general medical condition including fluid and electrolyte correction. If there is passage of flatus following PR examination or sigmoidoscopy, insertion of a flatus tube can also be useful.

$\mathrm{CT}$ of the abdomen and pelvis is an invaluable tool in the assessment of large bowel obstruction [15-16]. Although other imaging modalities can also be useful, CT is the gold standard and increasingly available in most hospitals [17]. In this particular case it confirmed a diagnosis of large bowel obstruction and accurately identified an unexpected cause.

Foreign material from previous a PEG tube (changed 2 years prior to presentation) was found impacted within rectum causing large bowel obstruction. This was addressed and removed safely during rigid sigmoidoscopy under GA. CT helped avoid escalation to major surgery and which resulted in speedy recovery and discharge from hospital.

We have identified scattered reports of bezoars, baroliths and faecoliths as a cause of bowel obstruction in the literature [18-20]. We have also noted a case where a vaginal foreign body resulted in large bowel obstruction, however, we could not find any cases of a foreign body within the rectum causing large bowel obstruction [21-22].

\section{Conclusion}

Clinical teams should always consider the varied causes for large bowel obstruction. Early CT imaging can confirm the diagnosis and cause of large bowel obstruction which guiding optimal management.

\section{Learning points}

- Urgent assessment of all cases of bowel obstruction

- Thorough exploration of past medical and surgical history 
- CT AP is an invaluable tool to confirm diagnosis and identify the cause and level of bowel obstruction

- Urgent treatment of the underlying cause (including surgery if necessary) will achieve the best results and relieve the symptoms

\section{Competing interests}

We declare that we have no competing interests.

\section{Authors' contributions}

Study conception and design:

\section{MR, SP}

Acquisition of data:

MR

Analysis and interpretation of data:

MR

Drafting of manuscript:

MR

Critical revision:

\section{Patient consent}

Informed consent obtained by LPA (Lasting Power of Attorney) as patient cannot consent for herself.

\section{References}

1. Blackburn G (1955) Large bowel obstruction. Postgraduate medical J 31: 246-249.

2. Markogiannakis H, Messaris E, Dardamanis D, Pararas N, Tzertzemelis D, et al. (2007) Acute mechanical bowel obstruction: clinical presentation, etiology, management and outcome. Am J of gastroenterology 13: 432-437. [Crossref]

3. Barnett W O, Little B R (1965) Obstruction of the large bowel. Southern medical J 58: 1493-1496.

4. Drozdz W, Lejman W, Tusiński M (2005) Mechanical bowel obstruction. Surgical problem at the turn of the XIX-XX century, and the XX-XXI century. One institutional experience. Przeglad lekarski 62: 105-10. [Crossref]

5. El-Masry N S, Geevarghese R (2015) Large bowel obstruction secondary to adhesive bands. J of surgical case reports 2015: 2042-8812. [Crossref]

6. Nanni G, Garbini A, Luchetti P, Ronconi P, Castagneto M (1982) Ogilvie's syndrome (acute colonic pseudo-obstruction): review of the literature (October 1948 to March 1980) and report of four additional cases. Diseases of the colon and rectum 25: 157 166. [Crossref]

7. Matsuo Y (1978) Degree of bowel distension on plain-radiographs--a surgicalradiological study of new criteria in mechanical intestinal obstruction. The Japanese of surgery 8: 222-227. [Crossref]
8. Jaffe T, Thompson W M (2015) Large-Bowel Obstruction in the Adult: Classic Radiographic and CT Findings, Etiology, and Mimics. Radiology 275: 651-663. [Crossref]

9. Keoplung S, Teerasamit W, Suvannarerg V (2013) Diagnosis of bowel obstruction added value of multiplanar reformations from multidetector $\mathrm{CT}$ in comparison with axial planes alone. $J$ of the Medical Association of Thai $=$ Chotmaihet thangphaet 96 : 1569-1577. [Crossref]

10. Ng H J, Yule M, Twoon M, Binnie N R, Aly E H (2015) Current outcomes of emergency large bowel surgery. Annals of the Royal College of Surgeons of England 97: 151-156. [Crossref]

11. Wang Z, Pan Z, Pan J, Sun W, Xu J, et al., (2012) Comparison of the diagnosis and treatment of mechanical bowel obstruction due to tumor or other causes. Zhonghua zhong liu za zhi [Chin J of oncology] 34: 57-60. [Crossref]

12. Gash K, Chambers W, Ghosh A, Dixon A R (2011) The role of laparoscopic surgery for the management of acute large bowel obstruction. Colorectal disease: the official $J$ of the Association of Coloproctology of GB and Ire 13: 263-266. [Crossref]

13. Halay F, Syphax B, Leffall L D (1971) Diagnosis and management of acute large bowel obstruction. J of the National Medical Association 63: 362. [Crossref]

14. Yeo H L, Lee S W (2013) Colorectal emergencies: review and controversies in the management of large bowel obstruction. $J$ of gastrointestinal surgery: official $J$ of the Society for Surgery of the Alimentary Tract 17: 2007-2012. [Crossref]

15. Jun L, ChangYi S (2015) Diagnostic Value of Plain and Contrast Radiography, and Multi-slice Computed Tomography in Diagnosing Intestinal Obstruction in Different Locations. Ind J of surgery 77: 1248-1251. [Crossref]

16. Beattie GC, Peters RT, Guy S, Mendelson RM (2007) Computed tomography in the assessment of suspected large bowel obstruction. ANZ J of surgery 77: 160-165. [Crossref]

17. Kushnerov AI, Min'ko BA, Pruchanskiǐ VS, Matveev VE (2002) Ultrasound study in the diagnosis of small and large intestinal obstruction. Vestnik rentgenologii $i$ radiologii 5: 39-45. [Crossref]

18. Shaw AG, Peacock O, Lund JN, Tierney GM, Larvin M et al., (2007) Large bowel obstruction due to sesame seed bezoar: a case report. $J$ of medical case reports 1:159. [Crossref]

19. Saunders MP (1990) Large bowel obstruction due to an impacted barolith--a delayed complication of a barium study. Postgraduate medical J 66: 684-685. [Crossref]

20. Narayanaswamy S, Walsh M (2007) Calcified fecolith--a rare cause of large bowel obstruction. Emergency radiology 13: 199-200. [Crossref]

21. Chaparala RPC, Fawole AS, Ambrose NS, Chapman AH (2004) Large bowel obstruction due to a benign uterine leiomyoma. Gut 53: 386-387. [Crossref]

22. Puneet KA, Khanna AK (2002) Evidence Services. Intravaginal foreign body--a rare cause of large bowel obstruction. $J$ of the Ind Medical Association 100: 671.

Copyright: ( 2018 Rezacova M. This is an open-access article distributed under the terms of the Creative Commons Attribution License, which permits unrestricted use, distribution, and reproduction in any medium, provided the original author and source are credited. 